\title{
VIOLÊNCIA OBSTÉTRICA: UMA FORMA DE VIOLAÇÃO AOS DIREITOS FUNDAMENTAIS DAS MULHERES
}

\section{ARTIGO ORIGINAL}

SANTANA, Jullyane Braga de ${ }^{1}$

SANTANA, Jullyane Braga de. Violência obstétrica: uma Forma de violação aos direitos fundamentais das mulheres. Revista Científica Multidisciplinar Núcleo Do Conhecimento. Ano 06, Ed. 06, Vol. 05, pp. 68-88. Junho de 2021. ISSN: 2448-0959, Link de acesso: https://www.nucleodoconhecimento.com.br/lei/violacao-aos-direitos, DOI: 10.32749/nucleodoconhecimento.com.br/lei/violacao-aos-direitos

\section{RESUMO}

O trabalho pretende analisar os princípios fundamentais e os direitos da mulher na legislação pós-constituinte, bem como o tratamento legal dado à violência obstétrica em países da américa latina, incluindo o Brasil. $O$ texto aponta como a violência obstétrica viola os direitos fundamentais das mulheres, analisando práticas realizadas por profissionais da saúde contra mulheres gestantes, parturientes e puérperas e situações que as caracterizam como violência, sob a ótica dos direitos fundamentais elencados na constituição federal de 1988. O artigo aborda o parto humanizado como meio de combate à violência obstétrica e melhora na efetivação do direito fundamental à saúde, por meio de métodos objetivos e de pesquisas bibliográficas, assim, almejando provocar uma discussão crítica sobre a matéria no cenário da doutrina constitucional. Fica evidente que a assistência humanizada nesse contexto ainda é desconhecida por muitas mulheres, o que é reflexo da falta de políticas públicas destinadas à informação.

Palavras-chave: Violência Obstétrica, Violação dos Direitos Fundamentais, Parto Humanizado, Direito Fundamental à Saúde.

\footnotetext{
${ }^{1}$ Graduada em direito pela Universidade Estácio de Sá. Pós-graduada em direito público pela Faculdade Legale. $\mathrm{RC}: 88111$

Disponível em: https://www.nucleodoconhecimento.com.br/lei/violacao-aos-direitos
} 


\section{INTRODUÇÃO}

O trabalho pretende analisar práticas violentas realizadas por profissionais da saúde contra mulheres gestantes, parturientes e puérperas, e como tais práticas violam direitos fundamentais das mulheres. Conjuntamente, analisar se a efetivação do parto humanizado seria a solução para a melhora na qualidade de assistência à saúde.

Diante às diversas ocorrências de tratamento desumanizado em que mulheres são submetidas desde o pré-natal até posteriormente ao parto, a violência obstétrica tem se mostrado como um obstáculo à efetivação de preceitos constitucionais e internacionais, que enaltecem a dignidade da pessoa humana. O tratamento humanizado nos hospitais está longe de ser realidade para grande parte das brasileiras, e isso se dá pela falta de sensibilização em construir políticas públicas eficientes e efetivas quanto à humanização do tratamento da mulher gestante, melhorando assim, a qualidade de assistência à saúde.

A relevância do trabalho pode ser considerada de irrefutável indispensabilidade, pois é notório o crescimento desse tipo de violência na sociedade contemporânea e a perpetuação de práticas que tornam a mulher invisível em um momento tão importante.

O objetivo geral da pesquisa é analisar práticas obstétricas e situações que as caracterizam como violência, sob a perspectiva dos direitos fundamentais elencados na Constituição Federal de 1988. No que tange aos objetivos específicos, apresentase primeiramente os direitos fundamentais e o que mudou na vida da mulher após a Constituição de 1988. Seguido da definição de como se caracteriza a violência obstétrica e das diversas formas em que elas podem ocorrer. Apresenta-se, também, as especificidades das práticas obstétricas caracterizadas como violência no ordenamento jurídico brasileiro. Por fim, analisa-se os benefícios do parto humanizado, bem como se com a sua efetivação os direitos fundamentais das mulheres gestantes, parturientes e puérperas seriam respeitados. 
Metodologicamente, este trabalho pauta-se em pesquisa bibliográfica, com o uso de livros e artigos que tratam da matéria, buscando consubstanciar o mesmo, com a opinião de doutrinadores; assim como em pesquisa de legislação, visando corroborar acerca da violência obstétrica e a violação dos direitos fundamentais das mulheres.

A primeira seção do trabalho versa sobe os direitos fundamentais, como se inserem na constituição de 1988 e quais os direitos das mulheres na legislação pósconstituinte; bem como um breve apontamento sobre alguns tipos de violência contra a mulher. A segunda seção aborda a violência obstétrica, procedimentos médicos que a caracterizam e os direitos da mulher gestante, parturiente e puérpera. A terceira, apresenta o tratamento legal dado à violência obstétrica em países da América do Sul, bem como no ordenamento jurídico brasileiro. Por fim, na quarta seção, analisa-se como se dá o parto humanizado no Brasil e se a sua concretização seria um meio de combate à violência obstétrica, resultando na efetivação do direito fundamental à saúde.

\section{OS DIREITOS FUNDAMENTAIS}

Os direitos fundamentais são os direitos mais básicos de qualquer ser humano, devendo esses serem aplicados a todos os indivíduos, os possibilitando desfrutar de uma vida digna. Tais direitos decorreram de um processo histórico evolutivo, motivo pelo qual a historicidade é uma das características dos direitos fundamentais.

Com o início do século $X X$ vieram cartas constitucionais marcadas pelas preocupações sociais, como se percebe com os textos da Constituição mexicana de 1917, Constituição de Weimar de 1919, etc.

A Constituição mexicana de 1917 passou a garantir direitos individuais com tendências sociais, como, por exemplo, direitos trabalhistas e a efetivação da educação. (MORAIS, 2011) Conforme aponta Ricardo Castilho:

A Revolução Mexicana foi a primeira das grandes revoluções do século XX. Foi considerada uma revolução social porque postulava a reforma agrária e a justiça social. Como movimento constitucionalista, cumpriu seu papel em 1917. A Constituição mexicana é reconhecida

RC: 88111

Disponível em: https://www.nucleodoconhecimento.com.br/lei/violacao-aos-direitos 
como a primeira constituição liberal do mundo, moderna para a época, porque garantia direitos civis e políticos e reformas liberais como a reforma agrária e uma avançada legislação trabalhista, além de abordar temas religiosos e educacionais. É a Constituição que ainda rege os Estados Unidos do México. (CASTILHO, 2018, p.88)

Ao fim da Primeira Guerra Mundial e a queda da monarquia na Alemanha, ocorreu a Proclamação da República de Weimar em 1919. A República de Weimar previa em sua Parte II os Direitos e Deveres fundamentais dos alemães, tais quais os direitos e garantias individuais, direitos relacionados à vida social, direitos relacionados à religião e às igrejas, direitos relacionados à educação e ensino e direitos referentes à vida econômica.

Em sentido universal, as declarações de direitos passaram a ser objeto de reconhecimento em documentos declaratórios de feição universal e teve como passo fundamental a criação da ONU em 1945 e a Carta das Nações Unidas, que consolidava a ideia de que os direitos fundamentais do homem deviam ser respeitados, que teve por consequência a Declaração Universal dos Direitos Humanos, que fora aprovada pela Assembleia Geral da ONU em 1948, em sessão ordinária. (SILVA, 2017)

Não obstante, destaca-se a crítica doutrinária a respeito da expressão "gerações" de Direitos Fundamentais, pois passa uma ideia errônea de sucessão no tempo, abandono do que foi conquistado anteriormente, o que não corresponde à realidade. É preferível pela doutrina atual o uso do termo "dimensões", e são elas cinco dimensões.

A primeira marcou a passagem do Estado autoritário para o Estado de direito, sendo caracterizada pelas liberdades individuais e pelo absenteísmo estatal. São direitos negativos, pois negam a intervenção estatal, sendo exercidos contra o Estado, limitando o poder de atuação dos governantes.

Já os chamados Direitos Fundamentais de segunda dimensão, que foi impulsionado pela Revolução Industrial europeia do século XIX, se tem a concepção de "igualdade", são os direitos sociais, econômicos e culturais, frutos da transição do Estado Liberal 
para o Estado Social. São direitos positivos, prestacionais, que obrigam o Estado a atuar positivamente, intervindo no domínio econômico e prestando políticas públicas de caráter social.

Os direitos fundamentais de terceira dimensão, os chamados "de fraternidade ou solidariedade", são os direitos difusos, coletivos. Decorreram de grandes mudanças pelas quais passaram a comunidade internacional e a sociedade de massa, por meio do desenvolvimento tecnológico e científico. Nesse caso não há que se falar em discussão acerca da posição do Estado, tal qual nas dimensões anteriores. Trata-se da compreensão que se tem do ser humano em relação aos outros seres humanos, pois são direitos reconhecidos ao homem pela mera condição humana, visando afirmar uma visão fraternal e solidária da humanidade. (LENZA, 2018)

Parte da doutrina considera direitos fundamentais de quarta dimensão os que decorrem da evolução da engenharia genética, relacionados à manipulação do patrimônio genético, processo que pode colocar em risco a existência humana. Outras correntes doutrinárias apontam como aqueles introduzidos pela globalização política, correspondendo à última fase de institucionalização do Estado social. Destacam-se o direito à democracia direta, à informação e ao pluralismo. Ingo Sarlet aponta que não se deve considerar apenas uma nova roupagem para direitos individuais, mas direitos fundamentais pertencentes a dimensão autônoma. (LENZA, 2018)

A quinta dimensão estaria relacionada ao direito a paz. Bonavides, entende que o direito à paz merece ser tratado em dimensão autônoma, afirmando que a paz é premissa da democracia participativa e supremo direito da humanidade. Alguns doutrinadores consideram, também, a evolução cibernética e a informática como direitos de quinta dimensão. (FURTADO, 2008)

Visto a importância dos direitos fundamentais para os homens desde os primórdios, cabe analisar seu impacto na Constituição Federal de 1988.

\subsection{OS DIREITOS FUNDAMENTAIS NA CONSTITUIÇÃO FEDERAL DE} 1988

$\mathrm{RC}: 88111$

Disponível em: https://www.nucleodoconhecimento.com.br/lei/violacao-aos-direitos 
Inicialmente, é conveniente apontar que a Constituição Federal de 1988, ou a chamada Constituição cidadã, por ter havido efetiva participação popular em sua elaboração e vigente até os dias atuais, é resultado da redemocratização do país e do compromisso das lideranças com o retorno a um Estado Democrático de Direito.

Trazendo no Título II os direitos e garantias fundamentais, as expos em cinco capítulos, quais sejam: direitos individuais e coletivos, direitos sociais, nacionalidade, direitos políticos e partidos políticos.

Tendo em vista o assunto a ser abordado neste trabalho, os direitos sociais, individuais e coletivos merecem destaque. Os direitos e garantias fundamentais são proporcionais, fundamentalmente, aos direitos ligados à pessoa humana e à sua personalidade, como a vida, a dignidade, a honra e a liberdade, estando previstos no art. $5^{\circ}$ da referida Constituição. Os direitos sociais são voltados para melhoria da condição de vida de hipossuficientes, buscando alcançar a igualdade social, que é fundamento do Estado Democrático e está previsto no art. 1ํ, IV.

O constituinte de 1988 estabeleceu a dignidade da pessoa humana como fundamento da República, tendo o direito à vida e à saúde como reflexos diretos da consagração desse fundamento. $O$ direito à saúde se firmou, também, como cláusula pétrea, visto estar diretamente ligado ao direito à vida.

O direito à saúde, hoje, apresenta um conceito mais amplo, o que anteriormente se tratava apenas do foco na ausência de enfermidade, um conceito negativo, evoluiu para um bem-estar físico, psíquico, social e cultural, assim considerado pelos próprios documentos e tratados internacionais e pela própria OMS. Se inclui também nesse conceito de qualidade de vida o direito à felicidade. É considerado um direito de natureza prestacional. (MÜLLER, 2014) Alguns autores consideram o direito à saúde como direito fundamental individual, direito de primeira dimensão; outros, como direito fundamental social, de segunda dimensão; outros, direito à solidariedade, direito de terceira dimensão; outros ainda, de quarta dimensão, como direito de proteção do futuro. A autora afirma que, na atualidade, existe um direito da saúde como direito 
individual, como direito social, como direito solidário, e como direito à saúde das pessoas futuras, que coexistem e não se anulam, a saber:

Direito da saúde individual - bem jurídico é a saúde individual, marco da relação médico/paciente (primeira geração).

Direito da saúde social - bem jurídico social, marco das prestações assistenciais, sanitárias e farmacológicas por parte do Estado, de natureza prestacional (segunda geração).

Direito da saúde solidário - bem jurídico coletivo, marco das políticas nacionais da saúde pública de curto e médio prazo, que impõe ao Estado a instrumentalização de políticas e ações concretas (terceira geração).

Direito da saúde das pessoas futuras - bem jurídico coletivo, marco das políticas de médio e longo prazo, que impõe ao Estado políticas e ações concretas (quarta geração). (MÜLLER, 2014, p.57)

Para Müller, por conseguinte, o direito à saúde é multidimensional, já que seu exercício implica a realização de vários níveis de direitos relacionados à qualidade de vida física, mental, entre outras. (MÜLLER, 2014)

Em um contexto geral, a Constituição de 1988 foi a que mais obteve participação popular em sua elaboração, se destacando a participação das mulheres, ambicionando conquistas em âmbito constitucional, assim, fazendo valer a democracia participativa.

É notório que com a chegada da Constituição de 1988 houve uma inovação em relação à proteção formal da cidadania, instituindo um extenso conjunto de direitos e garantias fundamentais, inclusive, garantindo direitos iguais para homens e mulheres no país. Ademais, o fortalecimento do anteriormente referido direito à saúde e, por conseguinte, o direito à vida.

\subsection{OS DIREITOS DAS MULHERES NA LEGISLAÇÃO PÓS- CONSTITUINTE}

Com o decorrer do tempo, a mulher já havia conquistado alguns direitos no Brasil, contudo, a Constituição por assegurar a participação popular em sua elaboração

$\mathrm{RC}: 88111$

Disponível em: https://www.nucleodoconhecimento.com.br/lei/violacao-aos-direitos 
permitiu ao movimento das mulheres que se incorporassem ao texto constitucional a maioria das reinvindicações formuladas por elas.

O movimento feminino foi muito importante para a mudança legislativa e social ocorrer. Atuaram em conjunto com o Poder Legislativo, apontando desigualdades e apresentando políticas públicas. Desde a década de 70, o movimento feminino luta por igualdade de direitos entre homens e mulheres.

Entre os princípios expostos no texto constitucional, é de grande importância o da igualdade formal, estando previsto no caput do art. $5^{\circ}$, onde diz que todos são iguais perante a lei, sem distinções.

Todavia, observou-se historicamente que o mero tratamento legal igualitário proveniente da igualdade formal não era suficiente para que as condições de vida igualitárias a todas as pessoas se garantissem. Consequentemente, no período de surgimento dos movimentos sociais se desenvolveu o conceito de igualdade material. Significa dizer que

Não mais se concebe o direito à igualdade como tão somente o tratamento previsto em lei, mas sim que o Estado deveria atentar para as diferentes realidades sociais vividas por todos os seus cidadãos e adotar medidas de forma a garantir que estes pudessem, de fato, ter igual acesso a direitos e bens da vida. (ALMEIDA, 2017, p. $100-101$ )

Como consequência da igualdade formal, o artigo $5^{\circ}$ (inciso $L$ ) expressamente assegura a garantia das presidiarias de permanecerem com seus filhos durante 0 período lactante. $\mathrm{O}$ art. $7^{\circ}$ veda a diferença de salários, de exercício em função e de critério de admissão por motivos de sexo, idade, cor ou estado civil. Como meio de proteção, de forma isonômica, o art. $40, \S 1^{\circ}$, III, a e b prevê tempo de serviço reduzido à mulher, e o artigo 201, § 70, I e II, determina tempo menor do que o homem para se aposentar. (ARAUJO, 2017)

É importante observar, também, os avanços obtidos sobre os direitos das mulheres em âmbito mundial, com a Convenção sobre a Eliminação de Todas as Formas de Discriminação contra a Mulher - CEDAW, por meio da Organização das Nações Unidas, e regional, com a Convenção Interamericana para Prevenir, Punir e Erradicar 
a Violência contra a Mulher - Convenção de Belém do Pará, por meio da Organização dos Estados Americanos.

A Convenção sobre a Eliminação de Todas as Formas de Discriminação contra a Mulher, adotada em 1979 pela Assembleia Geral das Nações Unidas, é considerada o documento mais importante de defesa dos direitos da mulher, sendo em 1983 assinada pelo Brasil e ratificada em 1984, pelo Congresso Nacional.

A Convenção Interamericana para Prevenir, Punir e Erradicar a Violência contra a Mulher, conhecida também como Convenção de Belém do Pará, foi adotada em 1994 pela Assembleia Geral da Organização dos Estados Americanos, e ratificada no Brasil no ano seguinte. É o acordo internacional sobre a violência contra a mulher mais importante, elucidando a violência contra a mulher, declarando os direitos protegidos e apontando os deveres dos Estados-parte, além de criar mecanismos interamericanos de proteção. (FROSSARD, 2006)

As conferências mundiais sobre a mulher constituíram também marcos inquestionáveis nesse processo. A 4ª Conferência das Nações Unidas sobre a Mulher, realizada em 1995 em Pequim, foi a maior e a mais importante delas por diversos fatores, inclusive pelo número de participantes que reuniu, os avanços conceituais e programáticos que propiciou e pela influência que continua a ter na promoção da situação da mulher. (FROSSARD, 2006)

Entretanto, basta uma breve análise da sociedade no contexto histórico atual para demonstrar o distanciamento entre a igualdade e a tão desejada justiça social, de forma que as mulheres ainda tenham suas vozes silenciadas diante de instituições nacionais.

O desequilíbrio acerca da igualdade de gênero se dá de diversas formas, inclusive através da violência, o que acaba contribuindo para a assimetria de poder entre os homens e as mulheres.

\section{IDENTIFICANDO A VIOLÊNCIA OBSTÉTRICA}


A violência obstétrica é caracterizada pelo apoderamento do corpo das mulheres e de seus processos reprodutivos por profissionais ou instituições de saúde, por meio de tratamentos desumanizados, abuso da condição de médico e patologização de processos naturais, resultando na perda da autonomia da mulher para decidir de forma livre e consciente sobre seu corpo e sexualidade. (defensoria pública do estado de são Paulo, 2013)

Acerca disso, Kondo sustenta:

É a violência cometida contra a mulher grávida e sua família em serviços de saúde durante a assistência ao pré-natal, parto, pós-parto, cesárea e abortamento. Pode ser verbal, física, psicológica ou mesmo sexual e se expressa de diversas maneiras explícitas ou veladas. Como outras formas de violência contra a mulher, a violência obstétrica é fortemente condicionada por preconceitos de gênero. (KONDO, 2014)

Uma em cada quatro. Esse é o número correspondente às mulheres vítimas de violência obstétrica no Brasil. Uma em cada quatro mães de filhos brasileiros sofreram com algum maltrato no momento do parto.

Em números, a pesquisa mais completa versando sobre o tema no país é a Mulheres brasileiras e gênero nos espaços público e privado, realizada pela Fundação Perseu Abramo, em 2010. A pesquisa aborda diversos pontos entre relação que a mulher tem com a sociedade, como a violência doméstica, sexualidade, divisão do trabalho entre homens e mulheres e a saúde reprodutiva. Nessa perspectiva, a pesquisa mostra uma visão da percepção das entrevistadas acerca da violência obstétrica.

$\mathrm{Na}$ pesquisa, 2.365 mulheres foram ouvidas, o que indicou uma realidade assustadora. Quando questionadas se haviam sofrido algum tipo de violência no momento do parto, $85 \%$ das mulheres que têm filhos responderam que não; $9 \%$ afirmaram que o mau trato aconteceu nas maternidades; $1 \%$, nos serviços de prénatal; e $2 \%$, em ambos. Dois por cento não responderam. Isso dá um total de $12 \%$ de mulheres que em algum momento foi vítima de algum tipo de violência obstétrica. 
Porém, na fase seguinte da entrevista, são listadas algumas opções de ações que são consideradas violência e é pedido às mulheres dizerem que aconteceram com elas, $e$ o resultado foi: $25 \%$ das entrevistadas afirmaram ter sofrido alguma das ações consideradas violência. (MACEDO, 2018)

Tais atos podem se dar principalmente por meio psicológico, físico e sexual.

\subsection{PROCEDIMENTOS PSICOLÓGICOS}

Como procedimento psicológico entende-se toda ação causadora de inferioridade, vulnerabilidade, instabilidade emocional, medo, insegurança, alienação, ocorrendo por via de ameaças, mentiras, humilhações, piadas, grosserias, chantagens, ofensas, omissão de informações, informações prestadas em linguagem pouco acessível, desrespeito ou desconsideração cultural. (BRASIL, 2012)

Partindo da premissa de que grande parte dos procedimentos adotados durante 0 parto não são informados ou suas necessidades não são esclarecidas, é crível a permanência de sequelas ainda piores que as físicas, por vezes muito mais profundas e intensas.

O dossiê elaborado pela Rede Parto do Princípio traz alguns relatos de mulheres apontando situações de abusos que sofreram:

Quando cheguei na maternidade, um plantonista veio fazer o exame de toque, depois chamou outro para fazer outro toque e chegaram à conclusão de que eu estava com $4 \mathrm{~cm}$ de dilatação. Fui levada para o centro cirúrgico sem me informar nada. Quando questionei o porquê eu estava naquela sala, o médico falou que minha estatura era baixa e provavelmente o bebê não passaria na minha pelve. Questionei a conduta dele e pedi para que ele me deixasse tentar o parto normal. Ele ficou visivelmente irritado e disse que lavava as mãos caso ruim acontecesse. Ele não quis mais me atender e me passou para outro plantonista. Depois de passar o tempo todo deitada na maca, pois não me permitiram me movimentar para ajudar no trabalho de parto, sem poder beber ou comer, com ocitocina no soro, sem acompanhante, fui para mesa de parto, amarraram minhas pernas, uma enfermeira subiu em cima da minha barriga e minha filha nasceu. Só depois de 7 horas após o parto levaram a minha filha para eu conhecer."

RC: 88111

Disponível em: https://www.nucleodoconhecimento.com.br/lei/violacao-aos-direitos 
Na manhã seguinte do parto o médico passou na porta da enfermaria e gritou: 'Todo mundo tira a calcinha e se deita na cama! Quem não estiver pronta quando eu passar vai ficar sem prescrição! ". A mãe da cama do lado me disse que já tinha sido examinada por ele e que ele era um grosso, que fazia toque em todo mundo e como era dolorido. Fiquei com medo e me escondi no banheiro. E fiquei sem prescrição de remédio para dor (BRASIL, 2012)

\subsection{PROCEDIMENTOS FÍSICOS}

Os procedimentos ditos físicos denotam ações incidentes sobre o corpo da mulher, que the causem dor ou algum dano físico, sem a comprovação de que realmente existem elementos que amparem sua necessidade. Dentre os procedimentos, os que mais ocorrem são a privação de alimentação, impedimento de movimentação, tricotomia, manobra de kristeller, uso rotineiro de ocitocina, cesariana sem indicação e o não uso de analgesia quando indicada.

Entre esses, a manobra de kristeller é reconhecida pelo dano à saúde e por ser ineficaz, causando à mulher dor e um trauma posterior, que seguirá por tempo indeterminável.

Acerca da cesariana eletiva, a Agência Nacional de Saúde publicou em 2015 um estudo chamado "Medidas de estímulo ao parto normal na saúde suplementar", afirmando que "parto é uma questão de saúde e a escolha do modelo deve ser pelo método mais adequado para cada caso e o mais seguro para a mãe e o bebê". A pesquisa aponta que o nascimento cirúrgico amplia em 120 vezes as chances de o bebê ter síndrome de angústia respiratória e triplica o risco de morte materna. Já para a mulher, a cesariana acarreta numa da perda de maior volume de sangue, infecções puerperais e acidentes anestésicos. Analisando o índice de cesarianas no Brasil, a pesquisa registrou que $55 \%$ dos partos realizados no país são cirúrgicos, sendo na saúde suplementar $84,60 \%$ e $40 \%$ na rede pública. (MINISTÉRIO DA SAÚDE, 2001)

O Brasil lidera mundialmente o ranking de cesarianas e para se adequar ao recomendável pela Organização Mundial da Saúde tem de reduzir de forma drástica a taxa, visto que o estabelecido é que até $15 \%$ dos nascimentos poderiam ser operatórios. (BRASIL, 2012)

RC: 88111

Disponível em: https://www.nucleodoconhecimento.com.br/lei/violacao-aos-direitos 


\subsection{PROCEDIMENTOS SEXUAIS}

Os procedimentos sexuais se dão por toda ação que é imposta à mulher violando sua intimidade, incidindo sobre sua integridade sexual e reprodutiva, tendo ou não acesso aos órgãos sexuais da mulher. Como exemplos cabe citar o assédio, a episiotomia, exames repetitivos sem esclarecimento e sem prévio consentimento, lavagem intestinal e imposição de certa posição no momento do parto.

Não obstante, os procedimentos anteriormente citados sejam violações à integridade sexual da mulher, a episiotomia merece destaque. É um procedimento cirúrgico em que ocorre um corte perineal da vagina até o ânus ou em direção à perna, por vezes sem anestesia, com a intenção de tornar a área de acesso ao canal vaginal de parto maior. Complicações comuns que resultam de uma episiotomia são dores, infecções, grande volume de sangramento e um risco maior de laceração no períneo nos próximos partos.

Ademais, por vezes ainda se realiza o "ponto do marido", com a finalidade de deixar a vagina mais apertada, preservando o prazer masculino e podendo ocasionar mais dor durante a relação sexual e infecção na mulher.

Conforme o dossiê "Parirás com dor" aponta, o procedimento ocorrendo no ritmo natural do parto, as chances do períneo da mulher se manter íntegro e sem lesão são grandes, assim, resultando em menos pontos e numa cicatrização mais eficiente do tecido.

A episiotomia realizada de forma rotineira e indiscriminada se configura uma violação aos direitos sexuais, reprodutivos e à integridade corporal feminina. (BRASIL, 2012)

\subsection{OS DIREITOS DA GESTANTE, PARTURIENTE E PUÉRPERA}

Os direitos oferecidos às gestantes resultaram da uma luta pelos direitos das mulheres desenvolvidos a partir de uma compreensão da necessidade de proteção à gestante e seu bebê. As legislações federais e municipais garantem às gestantes que estas possam receber atendimento especial, de acordo com a suas necessidades.

RC: 88111

Disponível em: https://www.nucleodoconhecimento.com.br/lei/violacao-aos-direitos 
Destaca-se que o Brasil tem obrigação formal perante à comunidade internacional de cumprir o previsto na Convenção para Eliminação da Discriminação contra as Mulheres. Outrora citada, a CEDAW prevê no art. 12 a eliminação da discriminação contra a mulher na área da saúde. Outrossim, dispõe que os Estados devem garantir às mulheres assistência apropriada durante na gravidez, no parto e pós-parto imediato, assegurando também uma nutrição de forma adequada durante a gravidez e a lactância, demonstrando a importância de se garantir o direito à saúde durante todo o ciclo reprodutivo das mulheres. Laura Davis Mattar aponta que "é possível afirmar que a CEDAW, a seu tempo, reconhece os direitos reprodutivos das mulheres e a necessidade de assegurá-los para alcançar a igualdade entre homens e mulheres e que o Brasil, sendo seu signatário, deve respeitá-los, protegê-los e implementá-los". (MATTAR, 2017)

No que tange ao respeito à maternidade, a Constituição em seu art. 6으 da concebeu proteção à maternidade e à infância.

A Lei do Acompanhante (11.108/2005) impõe ao Sistema Único de Saúde, rede própria ou conveniada a permitir que a mulher tenha um acompanhante durante todo o tempo, desde o trabalho de parto até o pós-parto.

Quando falamos do acompanhante, além da pessoa indicada pela parturiente, surge também o direito a uma doula, que é uma acompanhante treinada especialmente para dar o suporte físico e emocional que a gestante precisa, desde o pré-natal até o momento do parto. A presença das doulas acompanhando a gestante já é permitida em vários estados do Brasil.

No âmbito trabalhista, os direitos que protegem a mulher gestante e puérpera estão elencados no artigo 391 e seguintes.

Tão importante quanto no ambiente profissional, é que o ambiente estudantil e acadêmico afete o mínimo possível a vida da mulher. Por isso, são conferidos direitos à mulher que esteja nessas condições, tais quais: licença-maternidade sem prejuízo do período escolar, cumprir os compromissos escolares em casa a partir do oitavo 
mês de gestação etc. Ademais, Organização Mundial da Saúde promulgou os Dez Direitos da Gestante, sendo eles:

\begin{abstract}
Receber informações sobre gravidez e escolher o parto que deseja; Conhecer os procedimentos rotineiros do parto; Não se submeter a tricotomia (raspagem dos pelos) e a enema (lavagem intestinal), se não desejar; Recusar a indução do parto, feita apenas por conveniência do médico (sem que seja clinicamente necessária); Não se submeter à ruptura artificial da bolsa amniótica, procedimento que não se justifica cientificamente, podendo a gestante recusá-lo; Escolher a posição que mais Ihe convier durante o trabalho de parto; Não se submeter à episiotomia (corte do períneo), que também não se justifica cientificamente, podendo a gestante recusá-la; Não se submeter a uma cesárea, a menos que haja riscos para ela ou o bebê; Começar a amamentar seu bebê sadio logo após o parto; A mãe pode exigir ficar junto com seu bebê recém-nascido sadio. (ORGANIZAÇÃO MUNDIAL DA SAÚDE, 2019)
\end{abstract}

Destacam-se também Portarias do Ministério da Saúde, como a 569/2000 que instituiu o Programa de Humanização no Pré-Natal e Nascimento, a 1.067/2005 que instaurou a Política Nacional de Atenção Obstétrica e Neonatal e a 1.459/2011, também conhecida como Rede Cegonha.

Esses, e outros direitos da parturiente, podem ser analisados por ela e inseridos em um Plano de Parto. Por meio do Plano de Parto a mulher determina a quais procedimentos desejam ser submetida, quais seriam de fato eficazes e necessários, assim delimitando a atuação da equipe que a atenderá.

\title{
4. A VIOLÊNCIA OBSTÉTRICA EM PAÍSES SUL-AMERICANOS
}

Argentina e Venezuela foram os pioneiros na América do Sul a introduzirem a violência obstétrica no ordenamento jurídico. Na Argentina, a Lei do Parto Humanizado (25.929/2014), determina tanto os direitos dos pais quanto dos filhos durante 0 processo de nascimento. A lei não conceitua expressamente essa modalidade de violência, mas cuidadosamente detalha e específica direitos atinentes às gestantes, parturientes e puérperas, sejam eles:

a) de ser informada sobre as intervenções médicas que possam ocorrer durante os processos, de maneira que possa optar livremente quando existirem diferentes alternativas; b) de ser tratada com

RC: 88111

Disponível em: https://www.nucleodoconhecimento.com.br/lei/violacao-aos-direitos 
respeito, de modo individual e personalizado, que lhe garanta a intimidade durante o processo e leve em consideração seus padrões culturais; c) de ser considerada pessoa sã, de modo que facilite sua participação como protagonista de seu próprio parto; d) ao parto natural, com respeito aos tempos biológico e psicológico, evitando práticas invasivas e ministro de medicação que não estejam justificadas pelo estado de saúde da parturiente ou da criança; e) a ser informada sobre a evolução de seu parto, o estado da criança e que participe das diferentes ações dos profissionais; f) a não ser submetida a nenhum exame de intervenção cujo propósito seja de investigação, salvo consentimento manifestado por escrito, devidamente protocolado e aprovado pelo Comitê de Bioética; g) de estar acompanhada de uma pessoa de sua confiança durante todos os avanços do parto; h) de ter a criança consigo durante a permanência no estabelecimento sanitário, desde que o bebê não requeira cuidados especiais; i) a ser informada dos benefícios do aleitamento materno e receber apoio para amamentar; j) receber informações sobre os cuidar de si e da criança; k) ser informada sobre os efeitos adversos do tabaco, álcool e drogas sobre a criança e sobre si. (BRASIL, 2012)

A Argentina promulgou a Lei de proteção integral às mulheres (26.485/2009), para prevenir, sancionar, e erradicar a violência contra as mulheres nos âmbitos em que desenvolvem suas relações interpessoais.

A lei aponta formas de violência que se enquadram no conceito, tais quais: violência psicológica, física, sexual, econômica e patrimonial e simbólica, que podem se manifestar através de diferentes modalidades, também determinadas na lei, tais quais: violência doméstica, institucional, laboral contra as mulheres, contra a liberdade reprodutiva, obstétrica e midiática. Quando se inclui a violência obstétrica como uma modalidade de violência, a lei a conceitua do seguinte modo: "Aquela que exerce o profissional da saúde sobre o corpo e os processos reprodutivos das mulheres expressadas em um trato desumano, abuso de medicação e tratar como se patologia fossem os processos naturais, em conformidade com a Lei 25.929/11." (ARGENTINA, 2009)

A Venezuela reconheceu juridicamente a violência obstétrica em 2007, com o advento da Lei orgânica sobre o direito das mulheres a uma vida livre de violência. (VENEZUELA, 2007) Esta lei é mais firme e mais clara em relação aos delitos e possíveis punições. Estabelece 19 meios de violência dentro das quais a violência obstétrica está inserida. As intervenções realizadas por profissionais de saúde que 
são consideradas violência obstétrica dentro desta lei são: não atender emergências obstétricas, obrigar a mulher a parir em certa posição, impedir o apego inicial da criança sem causa justificada, alterar o processo do parto que deveria ser natural usando técnicas para aceleração sem o consentimento da mãe, praticar o parto cirúrgico quando houver condição para o parto natural.

A lei prevê, também, que a vítima pleiteie judicialmente indenização por eventuais danos sofridos, que se estendem também aos herdeiros se os danos tiverem como resultado a morte da mulher.

Não obstante, é importante ressaltar que somente a promulgação de uma lei dificilmente conseguirá romper com algum problema social. Mesmo o país sendo o primeiro a legislar sobre o tema, definido até as consequências a serem imputadas ao profissional da saúde, a lei falhou em mencionar os direitos das mulheres e seus filhos no momento do nascimento.

O fato desses países terem voltado sua atenção ao tema é digno de afeição, visto a forma como essa modalidade de violência tem se tornado frequente na vida das mulheres.

\subsection{A VIOLÊNCIA OBSTÉTRICA NO BRASIL}

O Brasil, diferente da Argentina e Venezuela, não possui uma lei federal específica versando sobre tema. No entanto, o ordenamento jurídico brasileiro possui legislação genérica estadual.

Santa Catarina editou a Lei 17.097/2017. No Mato Grosso do Sul foi promulgada a lei 5.217/2018. O Paraná, mais especificamente Curitiba, conta com a lei municipal 19.701/2018. O Estado de Pernambuco também possui lei acerca do tema, a lei 16.499/2018. Minas Gerais promulgou a lei 23.175/2018.

São Paulo conta com o Projeto de Lei 1.130/2017. Os projetos de lei 7.633/2014, 8.219/2017 e 7.867/2017, também versam sobre os direitos inerentes às mulheres na gestação, parto e puerpério, bem como formas de suprimir a violência obstétrica.

RC: 88111

Disponível em: https://www.nucleodoconhecimento.com.br/lei/violacao-aos-direitos 
Conquanto, práticas obstétricas consideradas violentas podem ser caracterizadas como crimes já tipificados no Código Penal, sejam eles: contra a honra, omissão de socorro, lesão corporal e homicídio. (PAES, 2018)

Enquanto em países mais desenvolvidos que o Brasil as mortes de gestantes, parturientes e puérperas se tornam uma realidade cada dia mais distante, aqui não se observa essa tendência quanto aos números, que chegaram a 69 por 100 mil, tendo a prática dessa violência contribuído grandemente para a elevação desses patamares, sendo aceitável como objetivo para o milênio 35 por 100 mil.

\section{O PARTO HUMANIZADO NO BRASIL}

O Ministério da Saúde buscou medidas para que a preocupação e valorização com o momento do parto fossem retomadas, entendendo que se trata de um processo fisiológico, onde a mulher deve ser o principal sujeito. Assim, com o intuito de melhorar a qualidade de assistência no acompanhamento do pré-natal, ao parto e puerpério para a mãe e para o filho, foi lançado pelo Ministério da Saúde o Programa Humanização no Pré-Natal e Nascimento, por meio da Portaria no 569/2000, que trouxe à conhecimento o termo parto humanizado. Assim é descrita a atenção humanizada do parto pelo Ministério da Saúde:

O conceito de atenção humanizada é amplo e envolve um conjunto de
conhecimentos, práticas e atitudes que visam a promoção do parto e
do nascimento saudáveis e a prevenção da morbimortalidade materna
e perinatal. Inicia-se no pré-natal e procura garantir que a equipe de
saúde realize procedimentos comprovadamente benéficos para a
mulher e o bebê, que evite as intervenções desnecessárias e que
preserve sua privacidade e autonomia. (MINISTÉRIO DA SAÚDE,
2001)

Dessa maneira, o parto humanizado tem a atenção voltada à parturiente, tornando a maternidade um momento especial para mulher, sendo ela o sujeito principal do processo, devendo ser amparada e acolhida pela equipe de saúde com base na dignidade da pessoa humana e respeito à suas vontades, sem se restringir à técnica. 
O termo "humanização" remete à ideia de respeito às escolhas da mulher, dessa forma até mesmo um parto cirúrgico pode ser humanizado, se essa decisão for tomada pela própria gestante como o melhor método de parto para si.

Lançada em 2003, a Política Nacional de Humanização, visa colocar em prática os princípios do SUS no cotidiano dos serviços de saúde, produzindo assim mudanças na forma cuidar.

O processo de humanização do nascimento envolve, principalmente, uma mudança de atitudes. Inicialmente do profissional de saúde que é parte integrante da equipe que presta atenção integral a mulher, revendo seus conceitos, deixando de lado seus preconceitos, para favorecer um acolhimento completo, técnico e humano à mulher. Envolve também a mudança de atitude da instituição, que deve estar estruturada e preparada para esta nova postura, incentivando, favorecendo, estimulando, treinando e controlando seus profissionais para desempenhar tais tarefas. Ademais, as instituições devem também estar administrativa e estruturalmente preparadas para 0 processo, amparadas e suportadas por normas e diretrizes emanadas pelas instituições responsáveis pela saúde no país. É neste contexto que o Ministério da Saúde tem envidado todos os esforços no sentido de estimular e propiciar a introdução destas novas práticas nas maternidades brasileiras. (MINISTÉRIO DA SAÚDE, 2001)

\subsection{O PARTO HUMANIZADO COMO MEIO DE COMBATE A VIOLÊNCIA OBSTÉTRICA E MELHORA NA EFETIVAÇÃO DO DIREITO FUNDAMENTAL À SAÚDE}

Apesar de o governo ter estabelecido o parto humanizado como regra, as mulheres ainda vivem um verdadeiro sorteio em que as chances de ela tomar alguma decisão sobre o próprio corpo dependem do bom humor dos plantonistas. Campanhas de esclarecimento e treinamento dos funcionários em humanização não têm sido suficientes para transformar esse quadro, e tanto na rede pública quanto na privada, mulheres ainda continuam sendo deixadas em segundo plano quando deveriam ser a protagonista.

$\mathrm{RC}: 88111$

Disponível em: https://www.nucleodoconhecimento.com.br/lei/violacao-aos-direitos 
Com tantos riscos, muitas mulheres têm deixado para ir ao hospital somente quando estão prestes a ganhar o bebê. As que têm condições de contratar uma equipe de acompanhamento pré-hospitalar o fazem, as que não têm contam com sua própria experiência no assunto.

O fato de não haver lei federal tratando da violência obstétrica, preconiza a ideia de uma aparente aceitação dos hospitais aos procedimentos feitos em suas dependências, nesse caso, não se observa a humanização do parto, uma compreensão do que aquela mulher está passando. Regras são criadas para um comportamento sistematizado dentro do hospital, formas como essa mulher deve agir, e nesse momento ela é culpabilizada caso não siga essas ideias. $E$ dois dos maiores desafios para a violência obstétrica ainda não ser tipificada em âmbito nacional são o fundamentalismo e o lobby das associações médicas e dos planos de saúde no Congresso, já que cesáreas geram mais lucros e evitam que médicos tenham que fazer plantão enquanto esperam o tempo natural do corpo da mulher.

O correto é que não fosse preciso de uma lei prevendo a assistência humanizada, já que o Brasil é signatário de diversos acordos internacionais sobre direitos das gestantes, porém não são prezados. O corpo da mulher não a pertence na hora do parto, pertence à equipe médica que a assiste.

Nesse momento, se faz importante análise dos direitos das mulheres à saúde a partir da decisão do Comitê para a Eliminação de Discriminação contra a Mulher no caso Alyne da Silva Pimentel contra o governo brasileiro. O caso Alyne é um dos muitos de morte materna evitável no país, pelo qual em 2011, o Estado brasileiro foi condenado internacionalmente por não cumprir com suas obrigações de proteger os direitos humanos relacionados à mortalidade materna. Esse caso reflete o padrão de violação sistemático ao direito à saúde, entre outros direitos humanos das mulheres grávidas no Brasil.

Os direitos humanos têm sido cada dia mais utilizados em casos judiciais no âmbito nacional e internacional, encorajando a implementar políticas para promoverem os direitos humanos das mulheres durante a gravidez, parto e puerpério. (GALLI, 2017) 
Para que ocorra o processo de humanização, os processos assistenciais na saúde devem acontecer por meio da participação de todos os envolvidos para garantir às recomendações feitas pelo Ministério da Saúde. O planejamento estratégico é um instrumento eficaz na busca da otimização dos serviços de saúde, por ser um método com um espaço democrático cujo envolvidos poderão assumir responsabilidades compartilhadas. Não obstante, muitos desafios ainda devem ser considerados. Sua constituição efetiva, não pode ser alcançada sem a mobilização das forças sociais que se agenciam para além do Estado. Nesse contexto, faz-se necessário que a Política Nacional de Humanização sirva como estratégia de mobilização social, ampliando seu modo de fazer para além da denúncia e da reivindicação de direitos. Esse é um modo de construir alternativas para se enfrentarem desafios que a saúde tem pela frente e que considera as diferenças e as singularidades, englobando valores, aspirações e necessidades referentes ao respeito ao cidadão.

É inquestionável que, em se tratando de assistência humanizada como um todo, ainda é desconhecido completamente essa forma de assistência por muitas mulheres, o que é reflexo da falta de políticas públicas destinadas à informação.

A implementação dessas políticas, sem dúvidas, acarretaria numa possível melhora na efetivação do direito fundamental à saúde, pois somente a informação dá a base necessária para habilitar a mulher a reconhecer quando práticas abusivas ocorrerem com ela e fazer suas escolhas de acordo com o que considera melhor pra si, consequentemente, caminhando para o combate à violência obstétrica.

\section{CONCLUSÃO}

Dado o exposto, o presente trabalho possibilitou analisar que a assistência à mulher nos períodos de pré-parto, parto e pós-parto ainda se insere num contexto de violações aos direitos fundamentais básicos das mulheres, e isso se dá por diversos fatores, como a desigualdade entre gêneros e a institucionalização do parto, que ainda se fazem presentes no país. 
Essa modalidade de violência contra a mulher ainda é silenciosa e institucional, o que faz com que passe despercebida na maioria dos casos, onde a mulher confunde procedimentos invasivos como imprescindíveis. $\mathrm{O}$ fato de o modelo de assistência intervencionista ao parto ser o mais utilizado no país faz com que essas práticas abusivas se perpetuem.

Um dos grandes desafios para o combate desse tipo de violência é a falta de lei federal específica versando sobre do tema. Por outro lado, a falta de informação das mulheres acaba por favorecer a continuação desta prática.

Em virtude dos fatos mencionados percebe-se que se faz necessária a implementação de políticas públicas eficientes destinadas à informação da população acerca da violência obstétrica, para que mais mulheres saibam que não precisam passar por procedimentos desnecessários e possam fazer suas escolhas de acordo com o que achar melhor para si e seu bebê, ocasionando numa assistência mais respeitosa em que seus direitos fundamentais são observados.

\section{REFERÊNCIAS}

ALMEIDA, Guilherme Assis de. Direito à igualdade e formas de discriminação contra a mulher. In FERRAZ, Carolina Valença (Coord.). Manual dos direitos da mulher. São Paulo: Saraiva, 2017. 707p.

ARAUJO, Luiz Alberto David. Princípios constitucionais, efetividade, e a proteção da mulher. In FERRAZ, Carolina Valença (Coord.). Manual dos direitos da mulher. São Paulo: Saraiva, 2017. 707 p.

ARGENTINA. Lei 26.485. Ley de protección integral a las mujeres. 2009. Disponível em:http://www.oas.org/dil/esp/Ley_de_Proteccion_Integral_de_Mujeres_Argentina.p df. Acesso em: 03 de abr. 2019, 21:49:33.

BRASIL. Senado. Parto Do Princípio. Dossiê da Violência Obstétrica "Parirás com dor". $2012 . \quad$ Disponível em: 
https://www.senado.gov.br/comissoes/documentos/SSCEPI/DOC\%20VCM\%20367.p df. Acesso em: 03 de abr. 2019, 11:10:58.

CASTILHO, Ricardo. Direitos Humanos. 5ª ed. São Paulo: Saraiva, 2018. 472p.

$\begin{array}{llll}\text { DEFENSORIA PÚBLICA DO ESTADO DE SÃO PAULO. A Violência Obstétrica } \\ \text { existe. } & 2013 . & \text { Disponível }\end{array}$
https://www.defensoria.sp.def.br/dpesp/repositorio/41/violencia\%20obstetrica.pdf. Acesso em 02 de abr. 2019, 19:43:09.

FROSSARD, Heloisa. Instrumentos Internacionais de Direitos das Mulheres. 2006. Disponível em: https://assets-compromissoeatitudeipg.sfo2.digitaloceanspaces.com/2012/08/SPM_instrumentosinternacionaisdireitosda smulheres.pdf. Acesso em: 02 de abr. 2019, 10:50:48.

FURTADO, Emmanuel Teófilo; MENDES. Ana Stela Vieira. 2008. Os Direitos Humanos de 5ª Geração Enquanto Direito à Paz e seus Reflexos no Mundo do Trabalho. Disponível em:http://www.publicadireito.com.br/conpedi/manaus/arquivos/anais/brasilia/02_335. pdf. Acesso em: 31 de mar. 2019, 17:52:19.

GALLI, Maria Beatriz. As Mulheres e o direito à Saúde: O Caso Alyne da Silva Pimentel. In FERRAZ, Carolina Valença (Coord.). Manual dos direitos da mulher. São Paulo: Saraiva, 2017. 707p.

KONDO, Cristiane Yukiko. Violência Obstétrica é Violência Contra a Mulher - Parto do Princípio e Fórum de Mulheres do Espírito Santo. 2014. 22p.

LENZA, Pedro. Direito constitucional esquematizado. 22. ed. - São Paulo: Saraiva, 2018. 1622p.

MACEDO, Thaís S. B. Com dor darás à luz: Retrato da violência obstétrica no Brasil. 2018. 81p. 
MATTAR, Laura Davis. Os direitos reprodutivos das mulheres. In FERRAZ, Carolina Valença (Coord.). Manual dos direitos da mulher. São Paulo: Saraiva, 2017. 707p.

MINISTÉRIO DA SAÚDE. Parto, aborto e puerpério: assistência humanizada à mulher. 2001. Disponível em: http://bvsms.saude.gov.br/bvs/publicacoes/cd04_13.pdf. Acesso em: 05 de abr. 2019, 09:11:27.

MORAES, Alexandre de. Direitos humanos fundamentais. 9a ed. São Paulo: Atlas, 2011. 432p.

MÜLLER, Águeda. Capítulo 2. La salud, um derecho humano. El derecho de la salud e los derechos humanos. Departamento de publicaciones - Facultad de Derecho UBA. 2014. 496p.

ORGANIZAÇÃO MUNDIAL DE SAÚDE. Direitos Da Gestante. Disponível em: http://www.fiocruz.br/biosseguranca/Bis/infantil/direitosdagestante.htm. Acesso em: 03 de abr. 2019, 20:24:57.

PAES, Fabiana Dal'mas Rocha. Violência Obstétrica, Políticas Públicas e a Legislação Brasileira. 2018. Disponível em: https://www.conjur.com.br/2018-out08/mp-debate-violencia-obstetrica-politicas-publicas-legislacao-brasileira. Acesso em: 04 de abr. 2019, 19:28:47.

SILVA, José Afonso da. Curso de Direito Constitucional Positivo. 40 ed. São Paulo: Malheiros, 2017. 936p.

VENEZUELA. Ley orgánica sobre el derecho de las mujeres a una vida Libre de violência. 2007. Disponível em: http://observatoriointernacional.com/?p=732. Acesso em: 03 de abr. 2019, 22:11:19.

Enviado: Abril, 2021.

Aprovado: Junho, 2021. 